\title{
REMEMBER WHAT, HOW, WHY? \\ LEARNING FROM THE ALAMO IN FILM
}

\author{
Allen W. Ellis \\ Northern Kentucky University
}

Initial consideration might suggest that the subject of the Alamo in film and television is not of sufficient substance for a college course--that it is too Texascentric; that the battle at the Alamo was of comparatively little significance. Such attitudes, however, do not stand up to careful scrutiny. Far more than a historical event, the Alamo is a cultural phenomenon. Far more than a key battle in the Texas war for independence from Mexico, the Alamo has taken on a number of meanings, eclipsing any importance it might hold as a mere military episode. For instance, does the Alamo represent human courage and sacrifice, or American racism and imperialism? Through readings, film screenings, lectures, and discussions, a history course built around the story of the Alamo can allow students to examine the values and attitudes expressed in and passed on by filmed representations of the Alamo. The Alamo has been the subject of American motion pictures since the early 1900s, and a new film has emerged approximately every ten to twenty years. This allows the opportunity to examine not only how the Alamo has been remembered over time, but also how these films are artifacts reflecting the times in which they were produced, deemed worthy of the enormous resources that have been poured into them.

I have had the privilege to teach such a course several times at Northern Kentucky University for a number of academic departments, in various combinations of popular culture studies, film studies, and history/film courses. I utilize portions of it in other courses to exemplify various cultural/historical points. It continually proves to be a highly satisfying experience, especially, as I have learned, if the proper theoretical groundwork is first established.

\section{Setting the Theoretical Groundwork}

For many years I have taught an introduction to popular culture course, using as its foundation the book, Popular Culture: An Introductory Text, by Jack Nachbar and Kevin Lause. Nachbar and Lause present two key concepts in their approach to popular culture studies: the Popular Culture Formula and the Funhouse Mirror. The Popular Culture formula asserts that "the popularity of a given cultural element (object, person or event) is directly proportional to the degree to which that element is reflective of audience beliefs and values." Consequently, the Alamo has so often been the subject

\footnotetext{
${ }^{1}$ Jack Nachbar and Kevin Lause, Popular Culture: An Introductory Text (Bowling Green, OH: Popular PIess, 1992), 5.
} 
of films and television because it reflects the beliefs and values of so many Americans. It is of value to ask students to identify examples of these beliefs and values.

Nachbar and Lause's Funhouse Mirror concept maintains that "Popular culture is a 'Funhouse Mirror' because it both reflects our 'image' back to us but also alters our image in the process of doing so." "So, the Alamo is our "image" in that it reflects our significant beliefs and values, yet it changes to some degree with each retelling, making it relevant to the given audience or zeitgeist. Alamo filmmakers start with the basic concepts and conventions, but tweak them to make them appealing (hopefully) to their audience. Thus, Martyrs of the Alamo in 1915 portrays Mexicans in a light that would be unacceptable to audiences of The Alamo in 2004; the Walt Disney and John Wayne versions of the event reflect beliefs/values with specific appeal to Cold War audiences.

It is also important as groundwork to establish academic objectivity, a concept that seems increasingly foreign to college students, possibly because of their familiarity with the Internet and its rapidly expanding culture of negativity. By most standards, many of the films shown in this course are not considered to be very good. In this course, such an approach is not acceptable. The films are not to be viewed as "good" or "bad," but as the products of their times, with such limits as budget and technology taken into consideration. "Boring" is also an unacceptable criticism, as it usually says more about the viewer than it does the films.

To help students write as scholars rather than reviewers, I refer them to the "Writing about Film" web page from the Dartmouth College Writing Program, which addresses "The Challenges of Writing about Film":

As you analyze and write about film, remember that you aren't writing a review. Reviews are generally subjective: they explore an individual's response to a film and so do not require research, analysis, and so on. As a result, reviews are often both simplistic (thumbs up, thumbs down) and "clever" (employing the pun-driven or sensational turns of phrase of popular magazines). While reviews can be useful and even entertaining pieces of prose, they generally don"t qualify as "academic writing."."3

Being objective also encompasses avoiding the pitfalls of presentism, holding people of the past to present-day attitudes and values. This topic leads to some fascinating discussions, especially when it comes to slavery-many of the Texians (as they called themselves) had emigrated from the American South, where slavery was a part of their

\footnotetext{
${ }^{2}$ Nachbar and Lause, 7 .
}

${ }^{3}$ Karen Gocsik, Dartmouth College Writing Program, "Writing About Film," last modified July 12, 2005. http://web.archive.org/web/20121213032601; http://www.dartmouth.edu/ writing/materials/studenu/ humanities/film/shtml (accessed September 28, 2013). 
culture and an indication of economic prosperity. Do we today give such people a break because slavery was then still to a large degree acceptable, or is slavery such a pure evil that there are no excuses for anybody at any time?

Finally, we establish the difference between truth and facts. That the sun rises every day is a truth, but it is not a fact; the sun does not move at all — we do! We have relatively little factual information when it comes to the Alamo, even such basics as the actual numbers of men fighting or killed. Alamo films, despite what their makers might insist, tend to play fast and loose with what we do know. Nonetheless, these films are certainly capable of conveying truth. There is a scene in 2004's The Alamo wherein Alamo commander William Travis addresses his assembled garrison, saying,

There have been many ideas brought forth in the past few months of what Texas is, and what it should become. We are not all in agreement. But I'd like to ask each of you what it is you value so highly that you are willing to fight and possibly die for. We call that Texas. ${ }^{4}$

There is no evidence that Colonel Travis ever made such comments, but what the filmmakers are conveying is certainly true. The reasons the men of the Alamo had for fighting might well have been as varied as the men themselves.

The first priority of the producers of popular culture is to make money. While it might be foolish for us to expect filmmakers to present historical facts within their products, it is not too much to ask that they capture the spirit of the historical event. Ron Howard, as producer for 2004's The Alamo, noted that "There's the historical truth, and there's the emotional truth. You want to get as close to the historical truth as you can, but nobody will care about the story if you miss the emotional truth." 5 And while the 2004 The Alamo is arguably the most historically-accurate Alamo film, there were nonetheless substantial changes made to history in an effort to make people "care about the story" (i.e., sell tickets). Recognizing that this is done and thinking about possible reasons why this is done is an essential element of this course.

Establishing these foundations has proven to be by far the most difficult aspect of the way I teach the course. It forces students to act in ways to which most are unaccustomed-as objective academic observers, thinking rather than feeling.

\section{Setting the Historical Groundwork}

The Alamo as a historical event is far beyond the ken of most students. While rarely is there a student who has not heard of the Alamo, most of what students know

${ }^{4}$ John Lee Hancock, The Alamo, DVD (Buena Vista, 2004).

${ }^{5}$ Paul Andrew Hutton, “Alamo Movies," Wild West (2004), 46-47. 
about the event comes from popular culture, but not their history classes. To set the historical framework for this event, it is imperative that students be limited to objective, trustworthy sources. After nearly fifty years as a student of the Alamo, I am satisfied with two sources to set this framework: the book, A Line in the Sand: The Alamo in Blood and Memory (NY: Simon and Schuster, 2001), and a documentary titled simply The Alamo (VHS, Arts and Entertainment Network and Greystone Communications, 1996), which is annoying in its title, because of the many such titles available and resultant misidentifications on Internet sources.

A Line in the Sand: The Alamo in Blood and Memory was written by Randy Roberts and James B. Olsen, both academic historians. They tell the Alamo story in three parts: The first provides the background leading up to the battle; the second part describes the battle itself and immediate aftermath; the third part examines the cultural legacies of the Alamo, reasons how and why it has been remembered, used and abused. Roberts and Olson cover a lot of ground in a work that is succinct, readable, and mostly accurate. I require students to read the first two parts as quickly as possible; chapters in the third part are assigned incrementally, as relevant to the film schedule.

The documentary, The Alamo, directed by Craig Haffner and narrated by Tom Berenger, is perhaps the best of a number of Alamo documentaries available. It is as accurate and even-handed as can be expected, beholden to neither political correctness nor mindless hero worship. I show this film on the first day of class, and then I assign students to write about and prepare to discuss next class anything they found particularly surprising or especially enlightening, challenging their preconceived notions or beliefs about the Alamo. Students often are surprised to learn, for instance, that native Mexicans fought alongside immigrant (legal and otherwise) Americans and Europeans in the Alamo, on behalf of Texas as an independent nation, not for the United States of America; that Davy Crockett, the most well-known Alamo defender, was actually a minor player in the Alamo story; and that the physical Alamo compound was huge, especially in comparison to the modest structure that stands in San Antonio today.

Clearly, popular culture had let most students down when it came to knowing about the historical Alamo. Popular culture tends to take the path of least resistance, often treating complexity even more cavalierly than facts.

\section{The Films}

With the theoretical and historical frameworks set, we begin to view the films. I expect students to identify continuously what the films have in common, how they differ, and how they reflect the times in which they were produced. My course is structured as a chronological survey, within the framework of "The Silent Alamo," "The Alamo Between World Wars," "The Alamo and the Cold War," "The Alamo in the Age of Cynicism and Political Correctness," and "The Alamo in the $21^{\text {st }}$ Century." The most important films screened are the following: 
Martyrs of the Alamo (1915):

The oldest known extant Alamo film. Produced while Mexico was being a major concern to the U.S. in the wake of the 1910 Mexican Revolution, it is the most blatantly racist and anti-Mexican of the Alamo films, and still packs a punch today. This is the first silent film most students have experienced--sometimes their first experience with a white actor in blackface. It immediately challenges their ability to view a film without refracting it through a twenty-first century lens.

Heroes of the Alamo (1937):

The first sound Alamo film. The Holy Texas Trinity of William Travis, James Bowie, and Davy Crockett are relatively minor characters, the emphasis being on the Dickinson family. As film historian Frank Thompson observes, the Dickinsons are not as interested in such abstractions as liberty or independence as much as simply preserving home and family. ${ }^{6}$ Such was the concern of many families during the Great Depression, when the film was made. The "heroes of the Alamo" in this film are regular folks, trying to avoid war and live in peace (another concern of the 1930s Americans), but taking a stand as necessary.

\section{Disneyland: "Davy Crockett at the Alamo" (TV, 1955):}

Disney's Crockett was the very personification of post-World War Two American virtue. He became a cultural and merchandising phenomenon, striking a chord with the emerging baby-boomer audience, and helping solidify the power of the emerging medium of television.

\section{The Alamo (1960):}

Greeted in 1960 with considerable critical disdain, The Alamo's cultural stock has risen over the years as the conservative politics of producer/director/star John Wayne fades from public memory. This epic film is often cited as an allegory for taking a stand against encroaching Communism. Students find a film that is deceptively complex, certainly more so than previous Alamo films, and as a bonus, they find it much more entertaining as well.

\section{The Alamo (2004):}

This film has proven to be most students' favorite, which is ironic given that The Alamo is one of the biggest Hollywood flops in recent years. Students are challenged to determine the reasons for this film's critical and commercial failure. The most realistic Alamo film, its heroes are portrayed as human beings rather than as demigods. Our current culture's fascination with celebrities is reflected by Billy Bob Thornton as a David Crockett struggling to live up to the media-created hype of Davy Crockett. By

\footnotetext{
${ }^{6}$ Frank Thompson, Alamo Movies (East Berlin, PA: Old Mill Books, 1991), 39.
} 
the time we view this film in our course, the role of those native Mexicans who supported the revolution is firmly established as a main part of the story.

Other films screened include Davy Crockett at the Fall of the Alamo (1926), Man of Conquest (1939), The Last Command (1955), Viva Max (1966), and the television productions American Playhouse: "Seguin" (1982), and The Alamo: 13 Days to Glory (1987).

\section{Conclusions}

Often, some students are initially apprehensive about a course focused on Alamo films. With few exceptions, they end up appreciating it. Some comments from students speak to this point. One student noted that "I did not realize how many angles there were to study [the Alamo] from, and this class has opened my eyes to those angles. It is interesting to see how the ideas about the Alamo have changed over time, and how the truth is continuing to unfold." Another added:

This course actually encompasses more material than many others because it is so multi-faceted. It's three courses in one: a history of film, a history of American culture, and a history of the Alamo. By studying the different ways the Alamo has been depicted in film, we learn about our country, our past, and ourselves ... we can't help but be left in awe at how one ninety-minute battle can be altered so many times and impacted our culture in so many ways.

A student from England, who had never heard of the Alamo, wrote: "While the Alamo is certainly a strong enough subject for a course, this class didn't just teach me about the Alamo, but also how to look at popular culture from a different perspective than the mainstream, and that makes it one of the most valuable classes I have taken at Northern."

Student success in this course is usually measured through four components: film response essays, discussion participation, midterm and final exams, and some large project, such as a research paper on a topic a student finds interesting. Following are examples of questions that I pose either as essay assignments or on exams. I also use some multiple choice and short answer/identification questions.

1) Nachbar and Lause say that Popular Culture is like a Funhouse Mirror because it reflects our "image" back to us while at the same time "altering" our "image." Explain what this means, with examples relevant to our study of the Alamo in film.

2) According to Roberts and Olsen, was the Texas Revolution based in racism and ethnocentrism, or in genuine, conflicting views of politics and individual rights? 
3) Explain how the values translated through the Alamo story are of broad cultural significance. Do they transcend the Texan or even American experience?

4) Describe how Mexicans in Alamo films have been depicted. How and why has the image of Mexicans evolved?

5) Identify and explain which Alamo film most reflects the time in which it was made.

Properly engaged students learn what facets of the Alamo story we historically and currently embrace, how these facets have been represented in film and television, and why these facets have had and continue to have such an impact. Reviewing over one hundred years of similar yet disparate depictions of the Alamo, students have the opportunity to learn of the complex sociopolitical origins and outcomes of the Texas Revolution, the differences between popular culture and history, how popular culture both reflects and alters a culture's beliefs and values, and how the Alamo should be considered a symbol for, rather than against, multiculturalism. To my great pleasure, these goals are usually met, and this is often the most rewarding course I have had the privilege to teach.

Note: If any readers would like to see a fuller list of films about the Alamo with comments from the author, contact him at the following address:

Allen W. Ellis

Professor of Library Services

Northern Kentucky University

Highland Heights, KY 41099-6101

E-mail: ellisa@nku.edu 